\title{
Comparison of Various Spectral Indices for Optimum Extraction of Tropical Wetlands Using Landsat 8 OLI
}

\author{
Syamani D. Ali ${ }^{1}$, Hartono ${ }^{2}$ and Projo Danoedoro ${ }^{3}$ \\ ${ }^{1}$ Faculty of Forestry, University of Lambung Mangkurat, Banjarbaru, Indonesia \\ ${ }^{2,3}$ Faculty of Geography, Universitas Gadjah Mada, Yogyakarta, indonesia
}

Received: 2019-10-11

Accepted: 2021-07-30

Keywords:

wetlands;

spectral indices;

Landsat $8 \mathrm{OLI}$;

South Kalimantan

Correspondent email: syamani.fhut@ulm.ac.id

\begin{abstract}
This research specifically aims to investigate the most accurate spectral indices in extracting wetlands geospatial information taking South Kalimantan, Indonesia, as an example of wetlands in tropical areas. Ten spectral indices were selected for testing their ability to extract wetlands, those are NDVI, NDWI, MNDWI, MNDWIs2, NDMI, WRI, NDPI, TCWT, AWEInsh, andAWEIsh. Tests were performed on Landsat 8 OLI path/row $117 / 062$ and 117/063. The threshold method which was used to separate the wetland features from the spectral indices imagery is Otsu method. The results of this research showed that generally MNDWIs2 was the most optimal spectral indices in wetlands extraction. Especially tropical wetlands that rich with green vegetation cover. However, MNDWIs2 is very sensitive to dense vegetation, this feature has the potential to be detected as wetlands. Furthermore, to improve the accuracy and prevent detection of the dryland vegetation as wetlands, the threshold value should be determined carefully.
\end{abstract}

@2021 by the authors. Licensee Indonesian Journal of Geography, Indonesia.

This article is an open access article distributed under the terms and conditions of the Creative Common

Attribution(CC BY NC) licensehttps://creativecommons.org/licenses/by-nc/4.0\%.

\section{Introduction}

Wetlands are ecosystems saturated with water, either seasonally or permanently (EPA, 2004). According to the Ramsar Convention on Wetlands 1993 (Matthews, 2013), based on the habitat, wetlands classified into marine and coastal wetlands, inland wetlands, and man-made wetlands. In the South Kalimantan Province, Indonesia, wetlands are one of the main features of the landscape.

The characteristics of tropical wetlands located in South Kalimantan Province are quite varied. For example, shallow water has a main characteristic, that is rich with green vegetation cover. On the deep water bodies (rivers) in this area, the waters have high enough levels of turbidity. In South Kalimantan, there are also quite a lot of open pit coal mining activities. The water inside the pits the rest of the coal mine will be mixed with the toxic minerals out of the mine. Hence, on the ground the pits look green. The green colour was formed distinct spectral signatures in multispectral optical imagery.

So far, various methods have been developed for the extraction of wetlands geospatial data automatically. For example, the Normalized Difference Water Index (NDWI) (McFeeters, 1996), Modified Normalized Difference Water Index (MNDWI) (Xu, 2006), and so forth. NDWI and MNDWI are the two most popular spectral indices for the extraction of water features or wetland features. Their ability to extract open water features or wetland features has been tested from several research results (McFeeters, 1996; Xu, 2006; Li et al., 2013; Jiang et al., 2014; Ashraf and Nawaz, 2015; Das and Pal, 2016; Du et al., 2016). Besides NDWI or MNDWI, there are also a number of other spectral indices that can potentially be used to separate wetland features from other features.

In general, spectral indices such as NDWI or MNDWI are actually developed to separate open water features from other features. Some research indicates that the spectral indices are very accurate in extracting the boundaries of water features. For example, Xu (2006) proved that MNDWI more accurate than NDWI when applied to the three water features, i.e. lakes, oceans, and rivers. Similar to Xu (2006), Li et al. (2013) also found that MNDWI more accurate than NDWI to the TM, ETM +, and ALI imagery. To further test MNDWI's capabilities, Jiang et al. (2014) developed the Automated Method for Extracting Rivers and Lakes (AMERL) for the extraction of rivers and lakes automatically from Landsat TM/ETM +. It was found that in general, MNDWI remains the best among the three other spectral indices.

$\mathrm{Du}$ et al. (2016) used MNDWI on the Sentinel-2 imagery, where the SWIR band of Sentinel-2 sharpened to 10 meters by a number of pan-sharpening method. Du et al. (2016) found that MNDWI with a combination of Principle Component Analysis (PCA) is more accurate than the NDWI and MNDWI with a combination of other pan-sharpening.

In other cases, other spectral indices have proven to be more accurate in extracting open water or wetlands features. For example, when Ashraf and Nawaz (2015) detect changes in the wetlands of the Baraila Lake (India) using four spectral indices, they found that in general NDWI is the most accurate method when verified using the field data. Similar to Ashraf and Nawaz, Das and Pal (2016) also found that NDWI was the most accurate spectral indices, when they compared 
six spectral indices. While Zhai et al. (2015) when comparing surface water extraction performances of four indices using Landsat TM and OLI, they found that Automated Water Extraction Index (AWEI) has the highest overall accuracy.

Kwak and Iwami (2014) developed a Modified Land Surface Water Index (MLSWI), they use it on flood inundation mapping using MODIS imagery and they test its accuracy using ALOS AVNIR 2. They found that MLSWI more accurate than Normalized Difference Vegetation Index (NDVI) and Land Surface Water Index (LSWI).

Several other researchers, such as Xie et al. (2016), they make further use of the spectral index to extract water features at the sub pixel level. They used MNDWI to separate the pure land pixel and pure water pixel in Spectral Mixture Analysis (SMA), for mapping the surface of the water of lakes and rivers automatically at sub pixel level.

Other researchers, such as Yang et al. (2015) combined spectral indices and single band multispectral imagery simultaneously to extractwater features. They use a number of spectral indices and single band on Landsat 8 OLI to extract the water bodies. Those are, the single-band threshold in band 5, multiband spectral relationship b2, b3, b4, b5, NDVI, NDWI, MNDWI, Normalized Difference Built-up Index (NDBI), TCT, and Hue, Intensity and Saturation (HIS). Where all of the spectral indices and bands are combined using deep learning algorithm, called Stacked Sparse Autoencoder (SSAE).

Although the spectral indices such as NDWI, MNDWI, NDVI, or others are accurate to separate open water features from other features, but it still needs to be studied further, whether these spectral indices are also accurate when used to separate wetland features from dryland features. Because, most of the wetlands in tropical areas has a spectral characteristic of water and green vegetation simultaneously. This research aimed to compare the accuracy of some of the spectral indices for optimizing the extraction of wetlands, by taking the case of the tropics area, that is, the South Kalimantan Province, Indonesia.

\section{Methods}

This research used two scenes of Landsat 8 OLI, the path/ row 117/062 and 117/063, the acquisition on April 22, 2015. Most of the wetlands in South Kalimantan to be in these two scenes. Imageries acquiring date selected on April because it was the rainy season. Therefore, the condition of wetlands is at the maximum extends.

Overall spectral indices in this study applied to Landsat 8 Operational Land Imager (OLI) surface reflectance imageries. Atmospheric correction methods used in this research was the Dark Object Subtraction 4 (DOS4) (Chavez, 1988; Chavez, 1996; Zhang et al., 2010; Hong et al., 2014).

Water Indices

Water indices is a generic term for all of the spectral indices intended to sharpen the water features. One of the water indices which is most extensively used is NDWI (McFeeters, 1996). According to McFeeters (1996), if the pixel values of NDWI are positive means the water features. Thus, the value of 0 by McFeeters (1996) is set as the threshold value. NDWI formulated by McFeeters (1996) as follows:

$$
\mathrm{NDWI}=\frac{\rho_{\mathrm{g}}-\rho_{\mathrm{n}}}{\rho_{\mathrm{g}}+\rho_{\mathrm{n}}}
$$

Where:

$r_{g}$ : green band

$\rho_{\mathrm{n}}$ : near infrared band

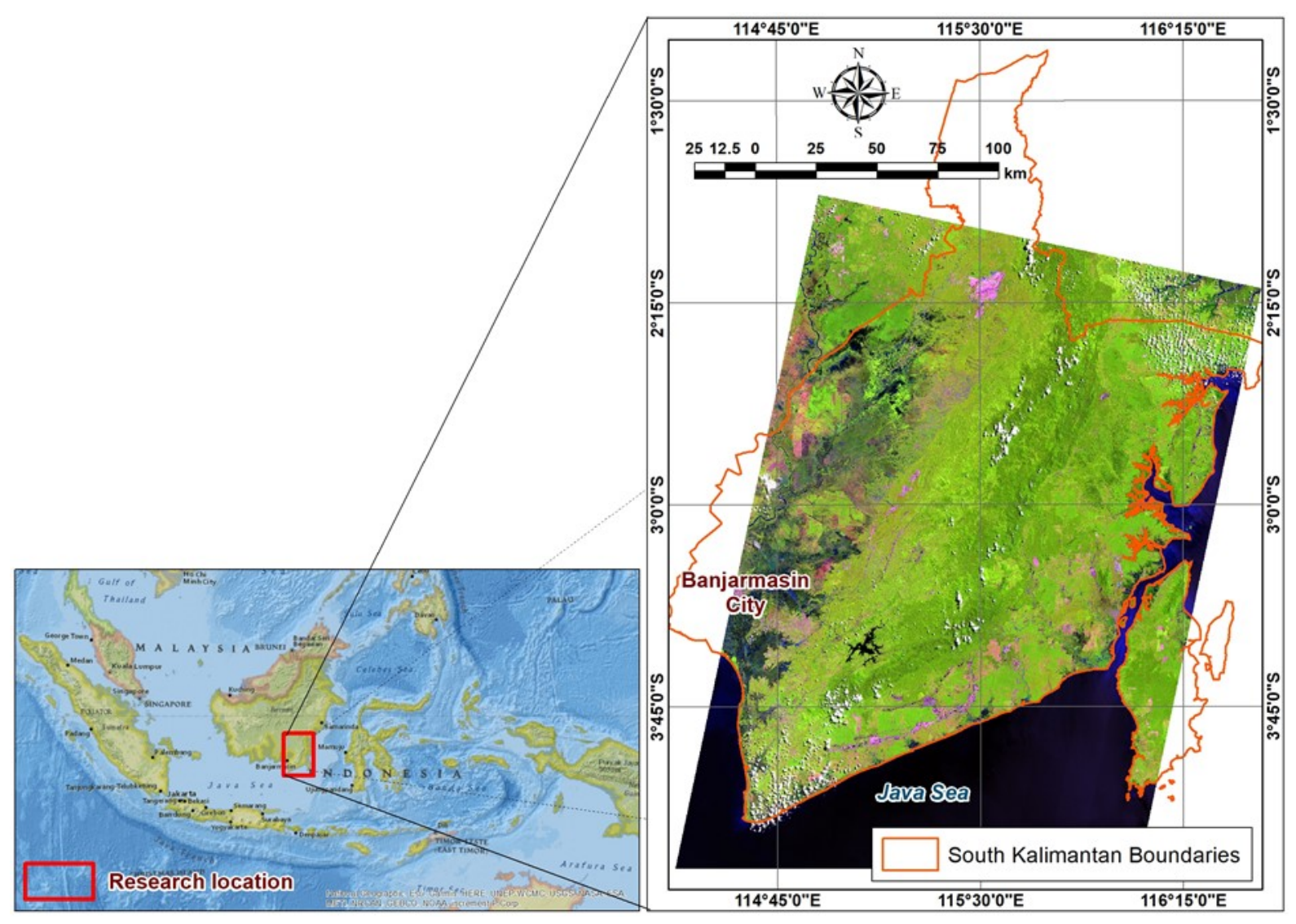

Figure 1. Research location 


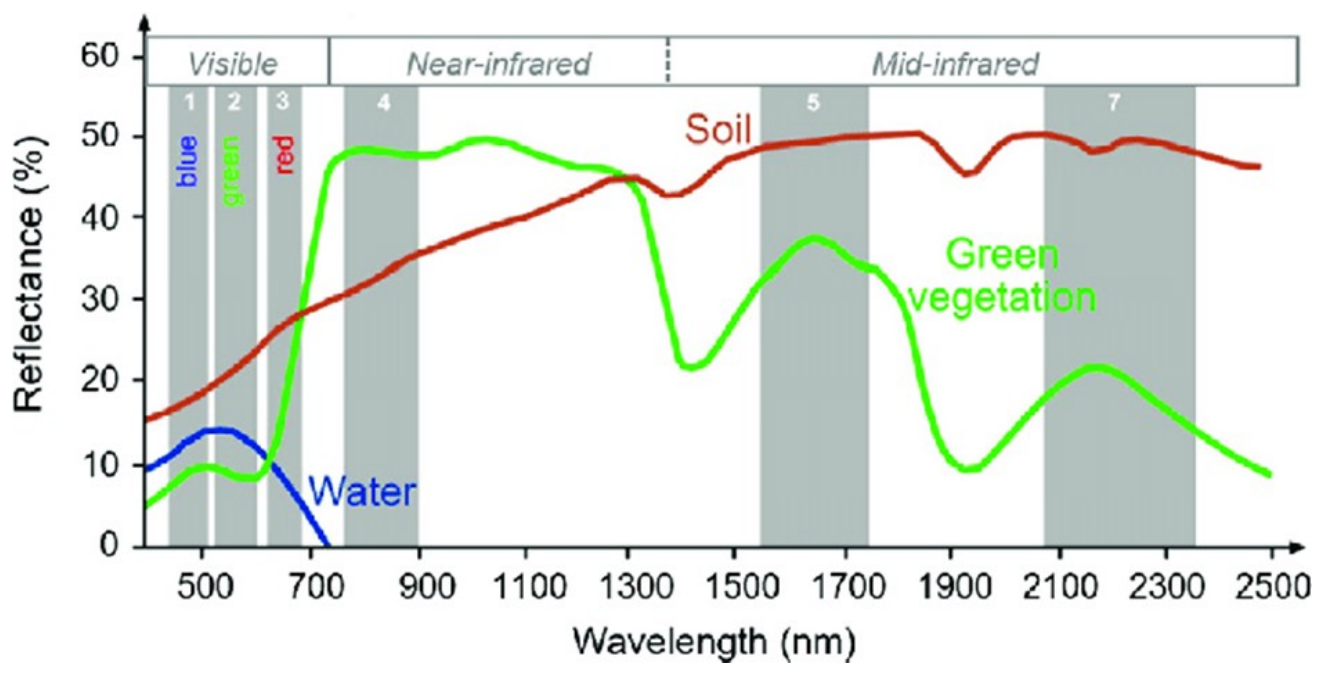

Figure 2. Spectral value curves on three base surface features (Chen et al., 2019)

Due to lack of NDWI in error detection features of the building, Xu (2006) modifying NDWI become MNDWI, by changing NIR band into SWIR. In this case, Xu (2006) using the SWIR1. The replacement of NIR with SWIR1 aims to suppress soil features (including buildings) in McFeeters's NDWI, because in the SWIR1 soil reflectances are higher than NIR. As seen in the spectral value curves in Figure 2.

$$
\text { MNDWI }=\frac{\rho_{\mathrm{g}}-\rho_{\mathrm{s}}}{\rho_{\mathrm{g}}+\rho_{\mathrm{s}}}
$$

Where:

$\mathrm{r}_{\mathrm{s}}$ : shortwave infrared band

In this research, we were also adding a water index modified from MNDWI, by replacing the SWIR1 in MNDWI with SWIR2. Thus, the MNDWI $\mathrm{I}_{\mathrm{s} 2}$ formula that we modified in this research is as follows:

$$
\mathrm{MNDWI}_{\mathrm{s} 2}=\frac{\rho_{\mathrm{g}}-\rho_{\mathrm{s} 2}}{\rho_{\mathrm{g}}+\rho_{\mathrm{s} 2}}
$$

Where:

$\mathrm{r}_{\mathrm{s} 2}$ : shortwave infrared 2 band

Xu (2006) replaces NIR with SWIR1 in NDWI (McFeeters, 1996) with the aim to suppress building features, because in the SWIR1, soil and building reflectance higher than NIR. In this research, we replace SWIR1 into SWIR2, with the aim to capture the spectral vegetation located above the wetlands. Because vegetation reflectance in SWIR2 is not as high as SWIR1 and NIR.

Besides NDWI, MNDWI and $\mathrm{MNDWI}_{\mathrm{s} 2}$, there are various other spectral indices to be tested in this research. Table 1 shows the full list of spectral indices which are capabilities will be compared in this study.

Information:

$\mathrm{r}_{\mathrm{ca}}$ : aerosol coastal bands (bands 1 Landsat 8)

$\mathrm{r}_{\mathrm{b}}$ : blue band (band 2 Landsat 8 )

$\mathrm{r}_{\mathrm{g}}$ : green band (band 3 Landsat 8 )

$\mathrm{r}_{\mathrm{r}}$ : red band (band 4 Landsat 8 )

$\mathrm{r}_{\mathrm{n}}$ : near infrared band (band 5 Landsat 8 )

$r_{s}$ : shortwave infrared band (band 6 or 7 Landsat 8 )

$\mathrm{r}_{\mathrm{s} 1}$ : shortwave infrared 1 band (band 6 Landsat 8 )

$\mathrm{r}_{\mathrm{s} 2}$ : shortwave infrared 2 band (band 7 Landsat 8 )

\section{Wetlands Extraction}

For the purpose of separating wetland features and nonwetland features from spectral indices imageries, some literature recommends a specific threshold value. However, in certain cases, the threshold value is often not optimal. According to Ji et al. (2009), the NDWI threshold is not a constant value, an appropriate NDWI threshold needs to be determined.

There are several methods of automatic thresholding used to classify digital imageries. One of the most popular automatic thresholding methods is Otsu thresholding (Otsu, 1979). In this research, the Otsu thresholding process is done using free open source public domain software, namely ImageJ (Schneider et al., 2012; Schindelin et al., 2015).

\section{Accuracy Accuracy Assessment}

Accuracy assessment was conducted using the Confusion Matrix (Stehman and Czaplewski, 1997), using a number of sample locations were selected purposively. In this case, the location of the sample represents multiple characters wetlands in South Kalimantan. Namely, mangroves, salt marshes, deep water (include reservoirs, canals, and coal open pits), peatlands, peatswamps, shrub-dominated wetlands, tree-dominated wetlands, fish ponds, swamp rice fields, irrigated land, freshwater marshes, and freshwater lake.Therefore, there are a total of 12 samples for wetland classes. Meanwhile, the number of sample pixels for each wetlands class are 4,495, 4,245, 10,904, 2,309, 6,739, 14,396, $2,265,3,217,6,597,2,307,5,020$ and 2,330 pixels respectively. For the purpose of assessing the deeper capabilities of each spectral index, the sample locations were also chosen purposively on various dryland features that have the potential to be detected as wetlands. In the appointment of the samples, the method used is knowledge-based. There are a total of 10 samples for dryland classes. Namely, built-up lands, barelands, grass, roads, dryland forest, dryland farms, garden (include mix garden, rubber plants, palm oil), and shrub and bushes. The number of sample pixels for each of these drylands classes are 1,236, 4,003, 2,377, 323, 6,445, $2,169,4,694$, and 8,075 pixels, respectively.

A confusion matrix is constructed for each spectral index, for example for NDWI a confusion matrix will be constructed, as well as for other spectral indices. The first 
Table 1. List of the spectral indices used in the research

\begin{tabular}{|c|c|c|c|c|}
\hline \multicolumn{2}{|c|}{ Spectral Indices } & \multirow{2}{*}{$\begin{array}{l}\text { Formula } \\
\frac{\rho_{n}-\rho_{r}}{\rho_{n}+\rho_{r}}\end{array}$} & \multirow{2}{*}{$\begin{array}{l}\text { Value of } \\
\text { Water } \\
\text { Negative }\end{array}$} & \multirow{2}{*}{$\begin{array}{l}\text { Reference } \\
\text { Rouse et al. (1973) }\end{array}$} \\
\hline NDVI & Normalized Difference Vegetation Index & & & \\
\hline NDWI & Normalized Difference Water Index & $\frac{\rho_{\mathrm{g}}-\rho_{\mathrm{n}}}{\rho_{\mathrm{g}}+\rho_{\mathrm{n}}}$ & Positive & McFeeters (1996) \\
\hline MNDWI & $\begin{array}{l}\text { Modified Normalized Difference Water } \\
\text { Index }\end{array}$ & $\frac{\rho_{\mathrm{g}}-\rho_{\mathrm{s} 1}}{\rho_{\mathrm{g}}+\rho_{\mathrm{s} 1}}$ & Positive & $\mathrm{Xu}(2006)$ \\
\hline MNDWI & $\begin{array}{l}\text { Modified Normalized Difference Water } \\
\text { Index with SWIR2 }\end{array}$ & $\frac{\rho_{\mathrm{g}}-\rho_{\mathrm{s} 2}}{\rho_{\mathrm{g}}+\rho_{\mathrm{s} 2}}$ & Positive & This research \\
\hline NDMI & Normalized Difference Moisture Index & $\frac{\rho_{\mathrm{n}}-\rho_{s}}{\rho_{\mathrm{n}}+\rho_{s}}$ & Positive & $\begin{array}{l}\text { Gao (1996); Wilson and } \\
\text { Sader (2002); Xiao et al. } \\
\text { (2002); Lacaux et al. (2007) }\end{array}$ \\
\hline WRI & Water Ratio Index & $\frac{\rho_{\mathrm{g}}+\rho_{\mathrm{r}}}{\rho_{\mathrm{n}}+\rho_{\mathrm{s}}}$ & $\begin{array}{l}\text { Greater } \\
\text { than } 1\end{array}$ & Shen $(2010)$ \\
\hline NDPI & Normalized Difference Pond Index & $\frac{\rho_{\mathrm{s}}-\rho_{\mathrm{g}}}{\rho_{\mathrm{s}}+\rho_{\mathrm{g}}}$ & Negative & Lacaux et al. (2007) \\
\hline TCWT & Tasseled-Cap Wetness Transformation & $\begin{array}{l}0.1877 r_{\mathrm{ca}}+0.2097 \mathrm{r}_{\mathrm{b}}+ \\
0.2038 \mathrm{r}_{\mathrm{g}}+0.1017 \mathrm{r}_{\mathrm{r}}+ \\
0.0685 \mathrm{r}_{\mathrm{n}}-0.7460 \mathrm{r}_{\mathrm{s} 1}- \\
0.5548 \mathrm{r}_{\mathrm{s} 2}\end{array}$ & - & Li et al. (2015) \\
\hline $\mathrm{AWEI}_{\mathrm{nsh}}$ & $\begin{array}{l}\text { Automated Water Extraction Index with } \\
\text { no shadow }\end{array}$ & $\begin{array}{l}4\left(r_{g}-r_{s 1}\right)-\left(0.25 r_{n}+\right. \\
\left.2.75 r_{s 2}\right)\end{array}$ & - & Feyisa et al. (2014) \\
\hline $\mathrm{AWEI}_{\mathrm{sh}}$ & $\begin{array}{l}\text { Automated Water Extraction Index with } \\
\text { shadow }\end{array}$ & $\begin{array}{l}\mathrm{r}_{\mathrm{b}}+2.5 \mathrm{r}_{\mathrm{g}}-1.5\left(\mathrm{r}_{\mathrm{n}}+\mathrm{r}_{\mathrm{s} 1}\right)- \\
0.25 \mathrm{r}_{\mathrm{s} 2}\end{array}$ & - & Feyisa et al. (2014) \\
\hline
\end{tabular}

accuracy assessment is done in general, where each spectral index is tested for its ability to separate wetlands and drylands. From the resulting confusion matrix, the overall accuracy, kappa coefficient, producer's accuracy, user's accuracy, commission error, and omission error are calculated to obtain quantitative descriptions of the capabilities of each spectral index. The recapitulation results of overall accuracy, kappa coefficient, producer's accuracy, user's accuracy, commission error, and omission errors can be seen in Table 2 .

Furthermore, to test the ability of each spectral index to recognize each wetland class, a confusion matrix was constructed for each spectral index in each wetland class. For example, for NDWI in the Mangroves class, a confusion matrix will be constructed. Furthermore, from the resulting confusion matrix the Producer's Accuracy value will be taken, to obtain a quantitative description of the ability of the spectral index to recognize one type of wetland. So we will get an overview of NDWI's ability to recognize Mangroves for example. Recapitulation of producer's accuracy values for each spectral index in each wetland class can be seen in Table 3.

The final step, to test the ability of each spectral index to avoid the detection of dryland features, a confusion matrix is constructed for each spectral index in each dryland class. For example, for NDWI in the Dryland Forest class, a confusion matrix will be constructed. Furthermore, from the resulting confusion matrix the Commission Error value will be taken, to obtain a quantitative description of the ability of the spectral index to avoid the detection of one type of dryland. So that a description of NDWI's ability to avoid detecting Dryland Forest as a wetland will be obtained, for example. Recapitulation of commission error values for each spectral index in each dryland class can be seen in Table 4 .

\section{Result and Discussion}

Visual appearance of wetlands in South Kalimantan varies in tone/colour on multispectral satellite imageries such as Landsat 8 . This shows quite a high degree of variation in spectral value of each type of wetlands. In the accuracy assessment, the samples were made for each type of wetlands. For the purpose to ensure that variations in the class of all wetlands are represented as possible, Region of Interest (ROI) made for every wetland types are distributed in several different locations. Figure 3 shows the Standard Deviation (SD) ROI of all wetlands in each band Landsat 8 OLI.

Of course, spectral indices such as NDWI cannot distinguish between mangroves and peatswamps, for example. Because spectral indices such as NDWI are only designed to recognize and separate water/wetlands from 


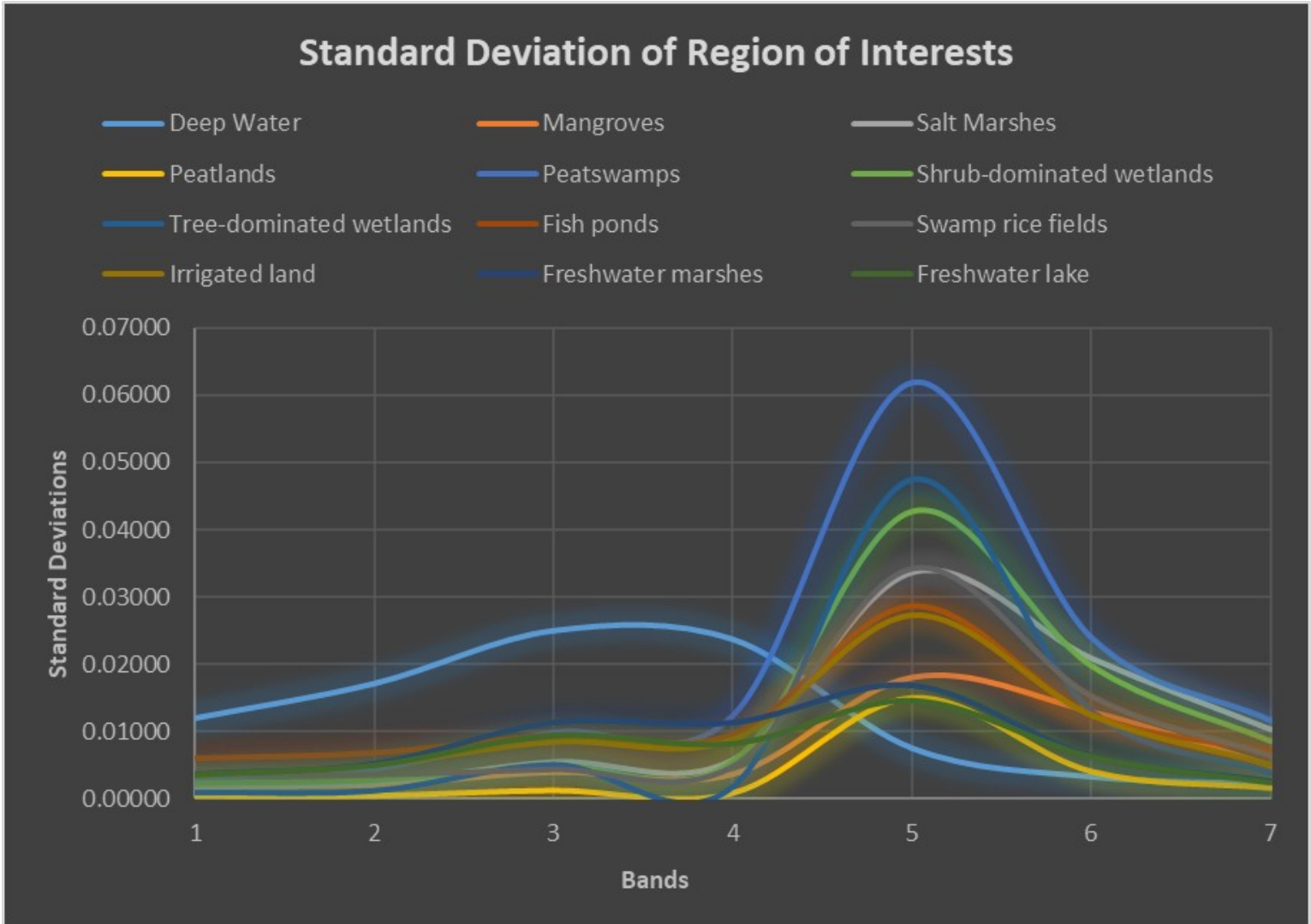

Figure 3. Standard Deviation of all wetlands types ROI in each band of Landsat 8 OLI

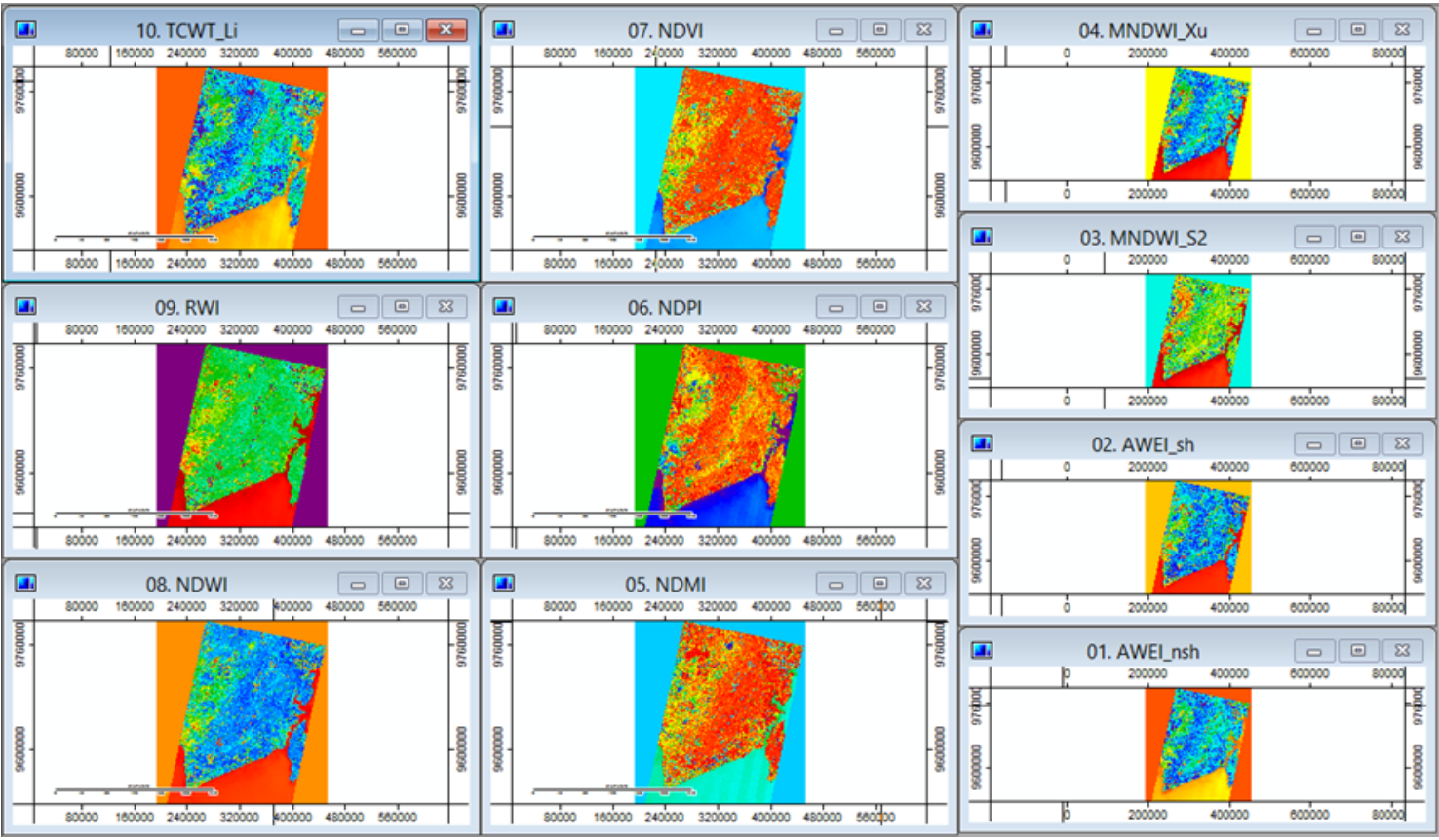

Figure 4. The result of the transformation of spectral indices on the SAGA application

dryland features. While mangroves and peatswamps are both wetland features. In fact, the thresholding imageries results of spectral indices contains only two classes, namely Wetlands and Non-wetlands. But for the sake of accuracy assessment, the accuracy assessment ROI is made on every types of wetlands in the research locations. It is intended that the spectral character of each wetland represented, and to provide an overview of each spectral indices extraction capabilities of each type of wetlands.
When the overall accuracy of the assessment is done, all types of wetland features are combined into a single class, namely the Wetlands. And all types of drylands features are combined into a single class, namely Non-wetlands. Figure 4 shows the results of the transformation of spectral indices were selected in this research. While Table 2 shows the results of Otsu thresholding and accuracy assessment results of each spectral index using the Confusion Matrix. Information: 
Table 2. The Otsu thresholding and accuracy assessment results using the Confusion Matrix

\begin{tabular}{|c|c|c|c|c|c|c|c|}
\hline Spectral Indices & Otsu Threshold & OA (\%) & Kappa & PA (\%) & UA (\%) & CE (\%) & OE (\%) \\
\hline NDVI & $\leq 0.21$ & 44.20 & 0.18 & 43.59 & 88.49 & 11.51 & 56.41 \\
\hline NDWI & $\geq-0.17$ & 45.19 & 0.19 & 44.84 & 89.73 & 10.27 & 55.16 \\
\hline MNDWI & $\geq-0.06$ & 68.59 & 0.50 & 84.22 & 99.74 & 0.26 & 15.78 \\
\hline $\mathrm{MNDWI}_{\mathrm{s} 2}$ & $\geq 0.07$ & 74.82 & 0.59 & 97.54 & 98.13 & 1.87 & 2.46 \\
\hline NDMI & $\geq 0.13$ & 32.68 & -0.14 & 38.86 & 60.48 & 39.52 & 61.14 \\
\hline WRI & $\geq 0.51$ & 73.02 & 0.50 & 98.61 & 84.61 & 15.39 & 1.39 \\
\hline NDPI & $\leq 0.05$ & 65.02 & 0.45 & 77.15 & 99.85 & 0.15 & 22.85 \\
\hline TCWT & $\leq 0.45$ & 59.32 & 0.37 & 66.37 & 99.95 & 0.05 & 33.63 \\
\hline $\mathrm{AWEI}_{\text {nsh }}$ & $\geq-0.55$ & 54.15 & 0.31 & 57.11 & 99.99 & 0.01 & 42.89 \\
\hline $\mathrm{AWEI}_{\mathrm{sh}}$ & $\geq-0.20$ & 62.46 & 0.41 & 72.53 & 98.87 & 1.13 & 27.47 \\
\hline
\end{tabular}

Table 4. Commission error for each spectral index and each drylands feature

\begin{tabular}{|c|c|c|c|c|c|c|c|c|}
\hline \multirow{2}{*}{$\begin{array}{l}\text { Spectral } \\
\text { Indices }\end{array}$} & \multicolumn{8}{|c|}{ Commission Error (\%) } \\
\hline & $\mathrm{Bu}$ & $\mathrm{Bl}$ & $\mathrm{Gr}$ & $\mathrm{R}$ & $\mathrm{F}$ & Df & $\mathrm{Gd}$ & $\mathrm{Sb}$ \\
\hline NDVI & 71.76 & 98.13 & 0 & 87.62 & 0 & 0 & 0 & 0 \\
\hline NDWI & 55.10 & 90.43 & 0 & 85.14 & 0 & 0 & 0 & 0 \\
\hline MNDWI & 0 & 0.05 & 0 & 37.15 & 0.47 & 0 & 0 & 0 \\
\hline $\mathrm{MNDWI}_{\mathrm{s} 2}$ & 0 & 0 & 0 & 0 & 18.65 & 0.05 & 0 & 0.15 \\
\hline NDMI & 1.70 & 0.10 & 100 & 5.57 & 100 & 91.47 & 100 & 100 \\
\hline WRI & 99.92 & 99.83 & 0 & 100 & 69.84 & 33.38 & 0.64 & 10.58 \\
\hline NDPI & 0 & 0.05 & 0 & 21.98 & 0.16 & 0 & 0 & 0 \\
\hline TCWT & 0 & 0 & 0 & 0 & 0.39 & 0 & 0 & 0 \\
\hline $\mathrm{AWEI}_{\mathrm{nsh}}$ & 0 & 0 & 0 & 0 & 0.06 & 0 & 0 & 0 \\
\hline $\mathrm{AWEI}_{\mathrm{sh}}$ & 20.47 & 1.27 & 0 & 95.05 & 0.14 & 0 & 0 & 0 \\
\hline
\end{tabular}

OA: Overall Accuracy

PA: Producer's Accuracy

UA: User's Accuracy

CE: Commission Error

OE: Omission Error

The use of a single method based on the spectral indices looks like it is not so qualified in the extraction of wetlands, as well as the extraction of the open water features. Because somehow wetlands are the composite features, which are mainly composed of water and vegetation. Islam et al. (2014) research results are not much different from the results of this research. Islam et al. (2014) found the spectral indices for mapping wetlands have the highest overall accuracy of $78 \%$.

Although in this research was found the spectral indices which has overall accuracy above $70 \%$, but when seen from the small Kappa coefficient, it seems overall accuracy was more to conditionally. However, this study is sufficient to provide an overview comparison of the relative accuracy of each spectral index, if used specifically for the delineation of wetland features.

In general, MNDWI, $\mathrm{MNDWI}_{\mathrm{s} 2}$, and WRI, are three spectral indices overall most accurately. However, the value of OA and Kappa both is not enough to describe the accuracy or optimality a digital imagery transformation method in extracting particular features. From OA has been seen that $\mathrm{MNDW}_{\mathrm{s} 2}$ implemented in this study is more accurate than MNDWI. However, when seen from the CE, map of wetlands resulting from MNDWI a little more accurate. For the next, we want to see, in which object successes and failures of each spectral indices located. Based on this, we examine the PA on each of the spectral indices, for each type of wetlands.

In testing the PA, each ROI at each wetland type tested separately on each thresholding results imagery of spectral indices. This is because, each thresholding results imagery of spectral indices does not distinguish among types of wetlands. Table 3 shows the PA for each spectral index and each wetland type.

Information:

Bu: Built-up lands

Bl: Barelands

Gr: Grass

R: Roads

F: Dryland forest

Df: Dryland farms

Gd: Garden (mixgarden, rubber plants, palm oil)

Sb: Shrub and bushes

Based on Table 3 and Table 4, it appears that NDMI cannot distinguish between dryland forest and wetlands forest. Likewise, the overall WRI has high accuracy, and as if it is able to recognize all types of wetlands with good, it fails on a number of dryland features and take it as wetlands. This translates into an overall accuracy WRI does not mean 
anything, because in fact it could not distinguish well between wetland features and some dryland features.

NDVI and NDWI that have the same character, they are also sensitive to built-up lands, roads, and barelands. NDPI better than NDVI and NDWI in distinguishing between built -up lands or barelands and wetlands. However, NDPI also slightly failed in distinguishing the paved roads to the wetlands. TCWT and AWEInsh are two spectral indices of the best in minimizing error detection wetlands. Since both spectral indices have the lowest CE. Different from AWEInsh,
AWEIsh disadvantaged in distinguishing between the paved roads to the wetlands.

MNDWI turned out to be problematic with paved roads in the wetlands. However, MNDWI failure to distinguish between wetlands and paved roads here occurs only as a result of Otsu thresholding is negative. MNDWIs2 was almost no problems with all the dryland features, except dryland forests. Furthermore, MNDWIs2 troubled with all the dense and dark vegetation features. As with all other spectral indices, MNDWIs2 also failed to recognize the

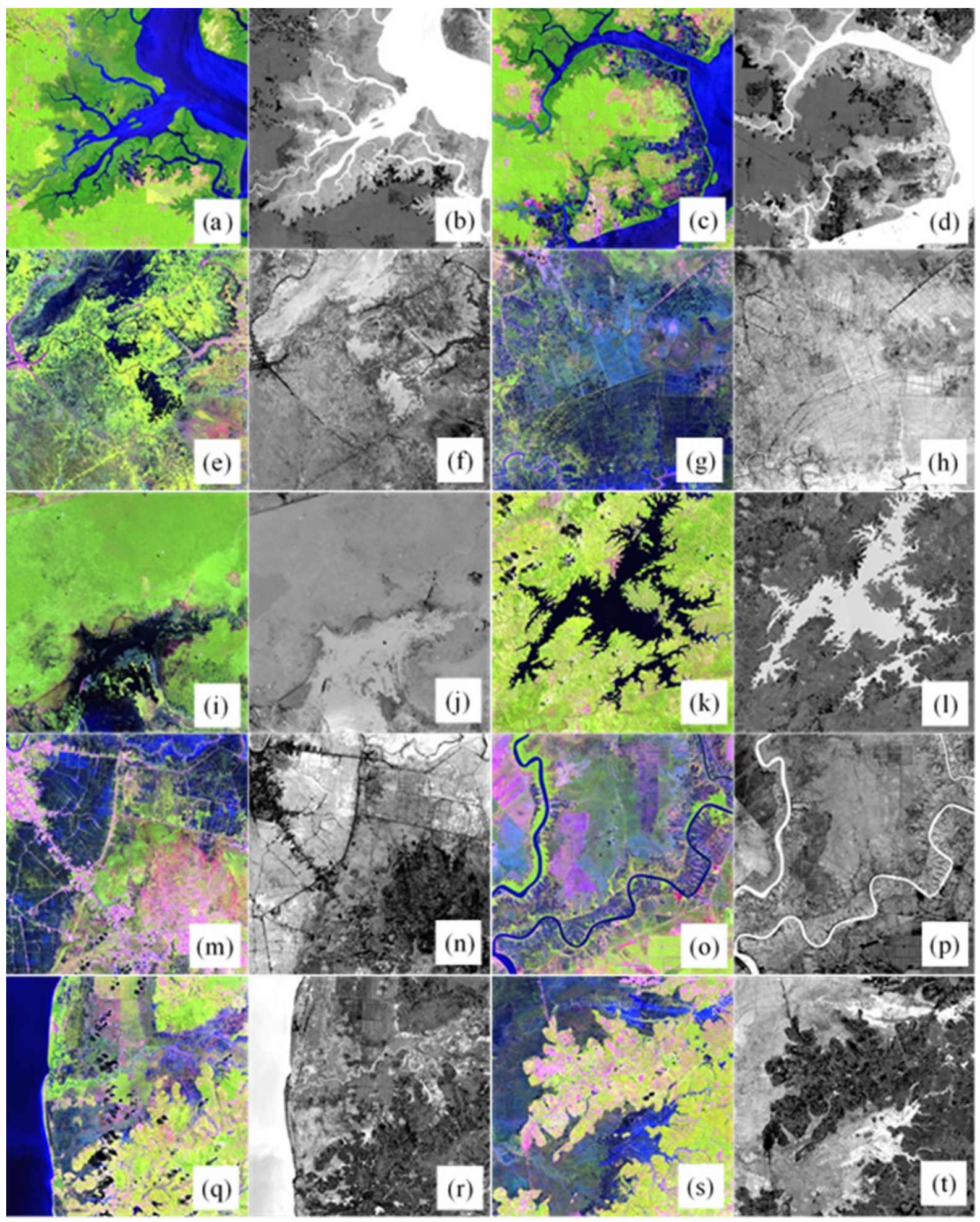

Figure 5. Comparison between Landsat 8 OLI composite 654 and $\mathrm{MNDW}_{\mathrm{s} 2}$

(a) and (b) mangrove; (c) and (d) fishpond; (e) and (f) freshwater lake and freshwater marshes; (g) and (h) irrigated land; (i) and

(j) peatlands and peatswamps; $(\mathrm{k})$ and (l) deep clear water (reservoir); ( $\mathrm{m}$ ) and (n) swamp rice fields and tree-dominated wetlands; (o) and (p) deep turbid water (river); (q) and (r) salt marshes; and (s) and (t) shrub-dominated wetlands. 
wetlands on which there are very bright vegetation features.

Based on the results of the accuracy assessment, it appears that MNDWIs2 is the most optimal spectral indices for the extraction of wetlands. Some experts previously also been modified MNDWI using SWIR2. Among them was Chen et al. (2005), Ji et al. (2009), Boschetti et al. (2014), and Islam et al. (2014).

MNDWI uses the green band and SWIR1 band. In SWIR1, vegetation features have a much higher reflectance value than in green. We can see this fact in wetlands which are dominated by dense vegetation, as seen in Table 5 and Figure 6. Table 5 and Figure 6 are constructed using the mangroves, peatlands, and tree-dominated wetlands samples from this research. Where in the wetlands which are dominated by dense vegetation, such as mangroves, peatlands, and tree-dominated wetlands, reflectance values for SWIR1 are higher than reflectance values for green. As a result, green substraction with SWIR1 in MNDWI causes vegetation features to be depressed. So that wetlands with dense vegetation are not detected as wetland features in MNDWI.

Not so with MNDWIs2 which uses green bands and SWIR2 bands. Where in SWIR2, the reflectance value of vegetation features is not as high as in SWIR1. Even the spectral value tends to be lower than green. We can also see this fact in Table 5 and Figure 6. Where in the wetlands which are dominated by dense vegetation, the reflectance values for SWIR2 are lower than reflectance values for SWIR1 or green. Thus, green substraction using SWIR2 will not suppress vegetation features as in MNDWI. As a result, wetlands with dense vegetation can still be detected in MNDWIs2. This makes MNDWIs2 the most optimal spectral index in extracting vegetation-rich wetlands such as tropical wetlands. Figure 5 shows the comparison between Landsat 8 OLI composite 654 imageries and the MNDWIs2 imageries.

Figure 6 shows a slightly unusual spectral values pattern, at least from two aspects. First, theoretically, vegetation features generally have low reflectance values in the blue band and coastal/aerosol. However, in Figure 6, the average reflectance of dense vegetation wetlands has a high reflectance value in blue and coastal/aerosol. This is because wetland vegetations are composite features between vegetation (chlorophyll) and water. Where the water feature itself has a high reflectance on the coastal and blue band. This fact makes the reflectance curve pattern of wetland vegetations unique, which is high in the NIR band and still quite high in the coastal and blue band. Second, theoretically, the highest reflectance value of pure water features is in the green band. However, in Figure 6, it can be seen that the

Table 5. Average reflectance values on each Landsat 8 band on three types of dense vegetation wetlands

\begin{tabular}{lccccccc}
\hline & \multicolumn{7}{c}{ Average reflectance values on each Landsat 8 band } \\
\cline { 2 - 8 } & Coastal/Aerosol & Blue & Green & Red & NIR & SWIR1 & SWIR2 \\
\hline Mangroves & 0.2259 & 0.2024 & 0.187 & 0.1609 & 0.393 & 0.1953 & 0.1476 \\
Peatlands & 0.2324 & 0.2082 & 0.1938 & 0.1639 & 0.4483 & 0.2341 & 0.1608 \\
Tree-dominated wetlands & 0.2342 & 0.2106 & 0.2014 & 0.1688 & 0.4041 & 0.2308 & 0.1614 \\
Average & 0.2308 & 0.2071 & 0.1941 & 0.1645 & 0.4151 & 0.2201 & 0.1566 \\
\hline
\end{tabular}

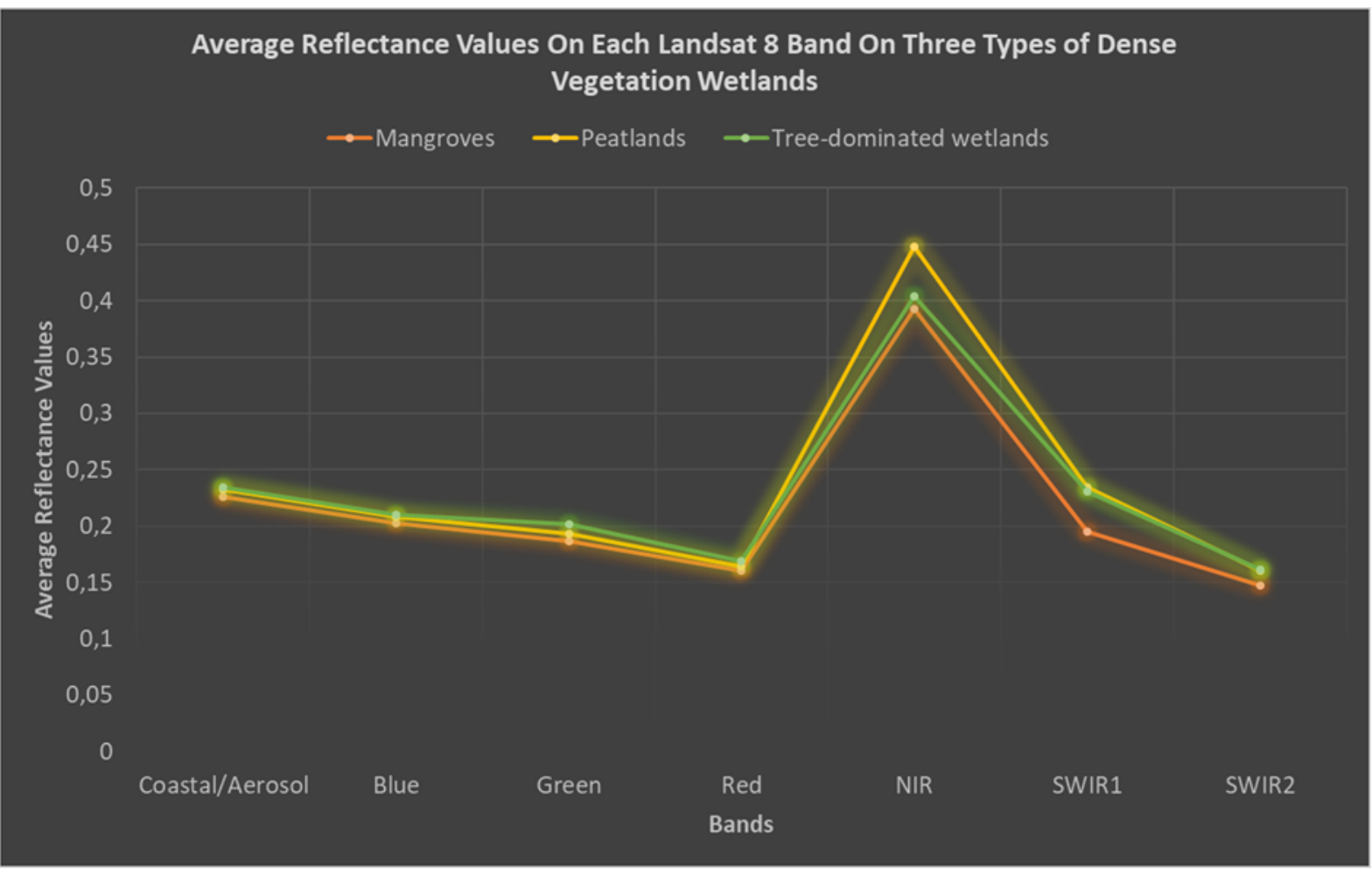

Figure 6. Average reflectance values on each Landsat 8 band on three types of dense vegetation wetlands 
highest reflectance values are in the coastal/aerosol and blue bands. The results of this research are similar (though not exactly the same due to different features) with the research results of Amani et al. (2018), as shown in Figure 7. Especially for vegetated wetlands such as bog, fen, and marsh.

Phenomena as shown in Figure 6 can occur due to various possibilities. The first possibility, the shadow of the tree crowns, or also called the sunlit crown. Sometimes the tree canopy forms a dark blue color, so they can appear like water features. Unlike pure water features which have the highest reflectance in green, shadow reflectance is higher in blue and lower in green (Li et al., 2009). Second, the spectral response of broadleaf forests shows low reflectance in the green band, and higher in blue and coastal/aerosols (Osgouei et al., 2019). In accordance with the facts, the dense vegetation wetlands in this research location are broadleaf forests.

MNDWIs2 can recognize deep water features as well as MNDWI. This is the implication of the use of green band that is able to capture reflections of open water features with high intensity, which is subtracted using SWIR2 band that do not capture reflections of open water features. Compared to MNDWI, MNDWIs2 still able to capture the reflection of background water or soil moisture beneath the canopy. In the MNDWIs2 imagery, built-up lands, road, and barelands, appear darker than MNDWI imagery. It is an implication of the subtraction with SWIR2. This can cause the dominant soil in wetlands background features will bring potential omission error to MNDWIs2.

(a)

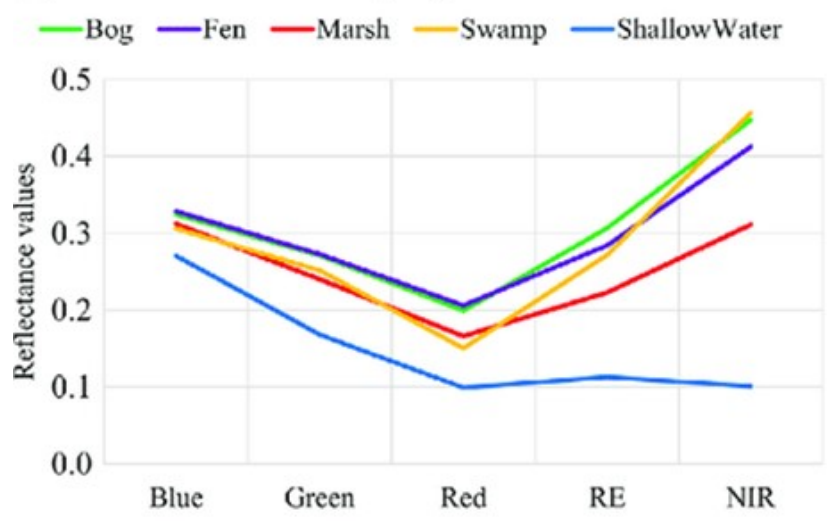

(c)

ASTER

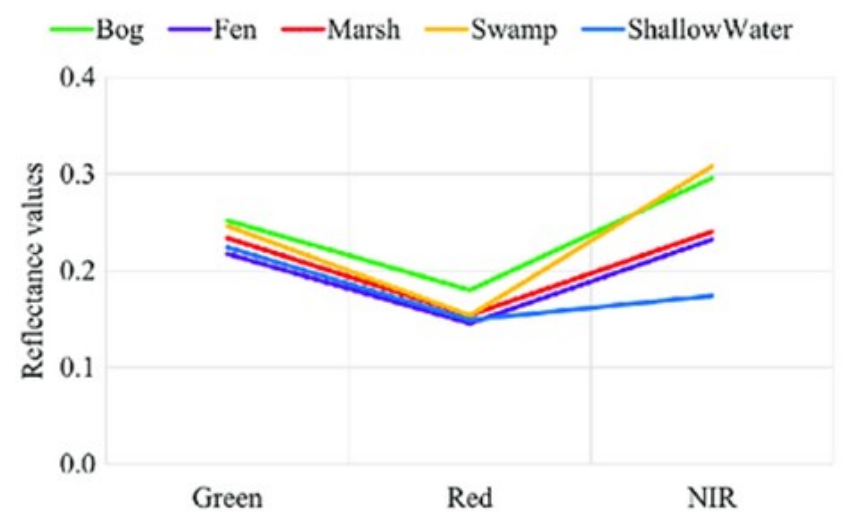

\section{Conclusion}

Based on this research, the spectral indices recorded the most accurate and optimal in extracting wetlands is $\mathrm{MNDWI}_{\mathrm{s} 2}$. But $\mathrm{MNDWI}_{\mathrm{s} 2}$ should be used wisely, given $\mathrm{MNDWI}_{\mathrm{s} 2}$ very sensitive to dense vegetations. $\mathrm{MNDWI}_{\mathrm{s} 2}$ also has potential error in wetlands with dominant soil background features. $\mathrm{MNDWI}_{\mathrm{s} 2}$ not only able to recognize the deep waters as well as MNDWI, but still able to capture the wetlands with vegetations on it.

Like MNDWI, MNDWIs2 also uses a green band. In spectral value curves, green band has the highest reflectance value of water features among all spectral bands. So that open water features can be detected properly by MNDWIs2. The advantage of MNDWIs2 is the use of SWIR2, where in spectral value curves SWIR2 band has a lower reflectance value of vegetation. So that substraction green with SWIR2 will not cause vegetation features to become depressed as in MNDWI.

The ability of $\mathrm{MNDWI}_{\mathrm{s} 2}$ in detecting peatlands with dense canopy as wetlands was very impressive. Given the peatlands actually not always saturated with water on the surface, most of them just has a very high water content in the ground with very high moisture surfaces. However, this condition is enough to make SWIR2 have very low reflections, so that green substraction using SWIR2 will enhance moist surfaces such as peatlands.

Based on the results of this research, $\mathrm{MNDWI}_{\mathrm{s} 2}$ can be considered as the Normalized Difference Wetlands Index (NDWLI). Of course, further research are needed to verify

(b) Sentinel $2 \mathrm{~A}$

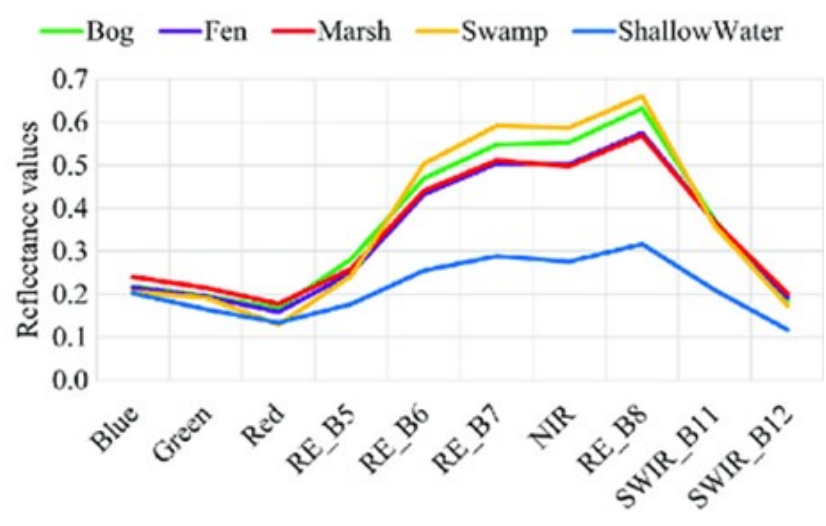

(d)

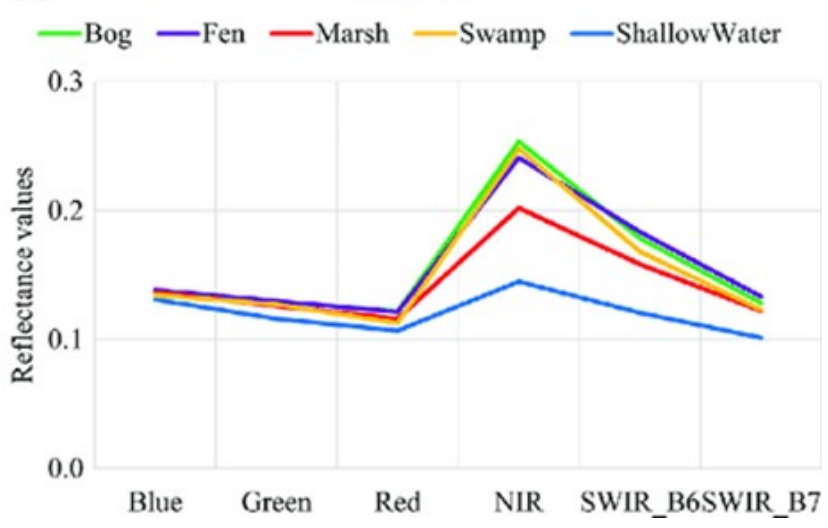

Figure 7. The spectral signature of wetlands, obtained from (a) RapidEye, (b) Sentinel 2A, (c) ASTER, and (d) Landsat 8 (Amani et al., 2018) 
the accuracy of the NDWLI formula. Especially if the formula be examined in other regions with different conditions, or be examined on other multispectral imageries.

\section{Acknowledgement}

The authors thank to the United States Geological Survey (USGS) for providing the Landsat 8 OLI imageries for free, as a main data of this research. This research was funded by the Spatial Data Infrastructure Development Center (PPIDS), University of Lambung Mangkurat. Digital image processing in this research was carried out at the Remote Sensing and Geographic Information System Laboratory, Faculty of Forestry, University of Lambung Mangkurat, Banjarbaru.

\section{References}

Amani, M., Salehi, B., Mahdavi, S. and Brisco, B.. (2018). Spectral analysis of wetlands using multi-source optical satellite imagery. ISPRS Journal of Photogrammetry and Remote Sensing, 114, 119-136.

Ashraf, M. and Nawaz, R..(2015). A Comparison of Change Detection Analyses Using Different Band Algebras for Baraila Wetland with Nasa's Multi-Temporal Landsat Dataset. Journal of Geographic Information System, 7, 1-19.

Boschetti, M., Nutini, F., Manfron, G., Brivio, P.A., Nelson, A. (2014). Comparative Analysis of Normalised Difference Spectral Indices Derived from MODIS for Detecting Surface Water in Flooded Rice Cropping Systems.PLoS ONE 9 (2), e88741. doi:10.1371/journal.pone.0088741

Chavez, P.S..(1988). An Improved Dark-Object Subtraction Technique for Atmospheric Scattering Correction of Multispectral Data. Remote Sensing of Environment, 24, 459479.

Chavez, P.S..(1996). Image-based Atmospheric CorrectionsRevisited and Improved. Photogrammetric Engineering and Remote Sensing, 62, 1025-1036.

Chen, D., Huang, J., and Jackson, T.J..(2005). Vegetation Water Content Estimation for Corn and Soybeans Using Spectral Indices Derived from MODIS Near- and Short-wave Infrared Bands. Remote Sensing of Environment, 98, 225-236.

Chen, Y., Guerschmana, J.P., Cheng, Z., and Guo, L..(2019). Remote sensing for vegetation monitoring in carbon capture storage regions: A review. Applied Energy, 240, 312-326.

Conrad, O., Bechtel, B., Bock, M., Dietrich, H., Fischer, E., Gerlitz, L., Wehberg, J., Wichmann, V., and Boehner, J..(2015). System for Automated Geoscientific Analyses (SAGA) v. 2.1.4. Geoscientific Model Development, 8, 1991-2007, doi:10.5194/ gmd-8-1991-2015.

Das, R.J. and Pal, S..(2016). Identification of Water Bodies from Multispectral Landsat Imageries of Barind Tract of West Bengal. International Journal of Innovative Research and Review, 4 (1), 26-37.

Du, Y., Zhang, Y., Ling, F., Wang, Q., Li, W., and Li, X..(2016). Water Bodies' Mapping from Sentinel-2 Imagery with Modified Normalized Difference Water Index at 10-m Spatial Resolution Produced by Sharpening the SWIR Band. Remote Sensing, 8, 354-372, doi:10.3390/rs8040354.

Feyisa, L.G., Meilby, H., Fensholt, R., and Proud, S.R..(2014). Automated Water Extraction Index: A New Technique for Surface Water Mapping Using Landsat Imagery. Remote Sensing of Environment, 140 (2014), 23-35.

Gao, B.C..(1996). NDWI A - Normalized Difference Water Index for Remote Sensing of Vegetation Liquid Water from Space. Remote Sensing of Environment, 58, 257-266.

Hong, G., Xing-fa, G., Young, X., Tau, Y., Hai-liang, G., Xiang-qin, W., and Qi-yue, L..(2014). Evaluation of Four Dark Object Atmospheric Correction Methods Based on XY-3 CCD Data
[Abstract]. Spectroscopy and Spectral Analysis, 34 (8), 22032207.

Islam, Md.A., Thenkabail, P.S., Kulawardhana, R.W., Alankara, R., Gunasinghe, S., Edussriya, C., and Gunawardana, A..(2008). Semi冈automated Methods for Mapping Wetlands using Landsat ETM+ and SRTM Data. International Journal of Remote Sensing, 29 (24), 7077-7106, doi: 10.1080/01431160802235878.

Jackson, T.J., Chen, D., Cosh, M., Li, F., Anderson, M., Walthall, C., Doriaswamy, P., and Hunt, E.R..(2004). Vegetation Water Content Mapping Using Landsat Data Derived Normalized Difference Water Index for Corn and Soybeans. Remote Sensing of Environment, 92, 475-482.

Ji, L., Zhang, L., and Wylie, B..(2009). Analysis of Dynamic Thresholds for the Normalized Difference Water Index, Photogrammetric Engineering and Remote Sensing, 75, (11), 1307-1317.

Jiang, H., Feng, M., Zhu, Y., Lu, N., Huang, J., and Xiao, T.. (2014). An Automated Method for Extracting Rivers and Lakes from Landsat Imagery. Remote Sensing, 6, 5067-5089.

Kwak, Y. and Iwami, Y..(2014). Nationwide Flood Inundation Mapping in Bangladesh by Using Modified Land Surface Water Index. ASPRS 2014 Annual Conference, Louisville, Kentucky, March 23-28, 2014.

Lacaux, J.P., Tourre, Y.M., Vignolles, C., Ndione, J.A., Lafaye, M. (2007). Classification of Ponds from High-spatial Resolution Remote Sensing: Application to Rift Valley Fever epidemics in Senegal. Remote Sensing of Environment, 106, 66-74.

Li, B., Ti, C., Zhao, Y., and Yan, X..(2015). Estimating Soil Moisture with Landsat Data and Its Application in Extracting the Spatial Distribution of Winter Flooded Paddies. Remote Sensing, 8, 3855, doi:10.3390/rs8010038.

Li, W., Du, Z., Ling, F., Zhou, D., Wang, H., Gui, Y., Sun, B., and Zhang, X..(2013). A Comparison of Land Surface Water Mapping Using the Normalized Difference Water Index from TM, ETM+ and ALI. Remote Sensing, 5, 5530-5549.

Li, W., Nie., J., Hu, H., Zhang, B., Wu, W. and Wang, L.. (2009) Dynamic change estimation of water resources based on remotely sensed imageries. Proceedings of SPIE 7495, MIPPR 2009: Automatic Target Recognition and Image Analysis, 74950Q.

Matthews, G.V.T..(2013). The Ramsar Convention on Wetlands: its History and Development. Ramsar Convention Bureau, Gland, Switzerland, p. 41.

McFeeters, S.K..(1996). The Use of the Normalized Difference Water Index (NDWI) in the Delineation of Open Water Features. International Journal of Remote Sensing, 17 (7), 14251432

Otsu, N..(1979). A Threshold Selection Method from Gray-level Histograms. IEEE Transactions on Systems, Man, and Cybernetics, 9, 62-69.

Osgouei, P. E., Kaya, S., Sertel, E. and Alganci, U.. (2019). Separating Built-Up Areas from Bare Land in Mediterranean Cities Using Sentinel-2A Imagery. Remote sensing, 11 (3), 345.

Rouse, J.W., Haas, R.H., Schell, J.A., Deering, D. W..(1973). Monitoring vegetation systems in the Great Plains with ERTS. Third ERTS Symposium, NASA SP-351 I, 309-317.

Schneider, C.A., Rasband, W.S., and Eliceiri, K.W..(2012). NIH Image to ImageJ: 25 Years of Image Analysis. Nature Methods 9(7), 671-675, PMID 22930834.

Schindelin, J., Rueden, C.T., and Hiner, M.C. et al..(2015). The ImageJ Ecosystem: An open Platform for Biomedical Image Analysis. Molecular Reproduction and Development, PMID 26153368.

Shen, L. and Li, C..(2010). Water Body Extraction from Landsat ETM+ Imagery Using Adaboost Algorithm. In Proceedings of 18th International Conference on Geoinformatics, 18-20 June, Beijing, China, 1-4. 
Stehman, S.V. and Czaplewski, R.L..(1997). Design and Analysis for Thematic Map Accuracy Assessment: Fundamental Principles. Remote Sensing of Environment, 1998 (64), 331-344.

United States Environmental Protection Agency (EPA).(2004). Wetlands Overview, EPA 843-F-04-011a. Office of Water, December 2004.

Wilson, E.H. and Sader, S.A..(2002). Detection of Forest Harvest Type using Multiple Dates of Landsat TM Imagery. Remote Sensing Environment, 80, 385-396.

World Wildlife Fund (WWF).(2004). Global Lakes and Wetlands Database: Lakes and Wetlands Grid (Level 3). Washington, D.C., http://www.worldwildlife.org/ publications/global-lakesand-wetlands-database-lakes-and-wetlands-grid-level-3.

Yang, L., Tian, S., Yu, L., Ye, F., Qian, J., and Qian, Y..(2015). Deep Learning for Extracting Water Body from Landsat Imagery. International Journal of Innovative Computing, Information and Control, 11 (6), 1913-1929.

Xiao, X., Boles, S., Frolking, S., Salas, W., Moore, B., et al..(2002). Observation of Flooding and Rice Transplanting of Paddy Rice Fields at the Site to Landscape Scales in China using VEGETATION Sensor Data. International Journal of Remote Sensing, 23, 3009-3022, doi:10.1080/01431160110107734.

Xie, H., Luo, X., Xu, X., Pan, H., and Tong, X..(2016). Automated Subpixel Surface Water Mapping from Heterogeneous Urban Environments Using Landsat 8 OLI Imagery. Remote Sensing, 8 (7), 584-599.

$\mathrm{Xu}, \mathrm{H}$. .(2006). Modification of Normalized Difference Water Index (NDWI) to Enhance Open Water Features in Remotely Sensed Imagery. International Journal of Remote Sensing, 27 (14), 3025 -3033, doi: 10.1080/01431160600589179.

Zhai, K., Wu, X., Qin, Y., and Du, P..(2015). Comparison of Surface Water Extraction Performances of Different Classic Water Indices using OLI and TM Imageries in Different Situations. Geo-spatial Information Science, 18 (1), 32-42, doi: 10.1080/ 10095020.2015.1017911.

Zhang, Z., He, G., and Wang, X..(2010). A Practical DOS ModelBased Atmospheric Correction Algorithm. International Journal of Remote Sensing, 31 (11), 2837-2852. 